\title{
Multi-Level And Multi-Actor Governance Of National Health Insurance Scheme In Ghana: An Exploration Of The Perceived Challenges In The Bosumtwi District
}

\section{Nicodemus Osei Owusu ${ }^{1}$, Nana Yaw Oppong ${ }^{2}$, Agnes Tweneboah Mensah ${ }^{3}$}

\author{
${ }^{1}$ Department of Management, School of Business, University of Cape Coast, Cape Coast, Ghana \\ ${ }^{2}$ Department of Human Resources, School of Business, University of Cape Coast, Cape Coast, Ghana \\ ${ }^{3}$ Department of Environment and Resource Studies, Faculty of Integrated Development Studies, University \\ for Development Studies, Wa Campus, Ghana \\ ${ }^{1}$ nowusu@ucc.edu.gh, ${ }^{2}$ noppong@ucc.edu.gh, ${ }^{3}$ agnesb23.nm@gmail.com \\ DOI: https://doi.org/10.18196/jgpp.61107 \\ Article Info \\ Article history: \\ Received 12 Des 2018 \\ Revised 2 Jan 2019 \\ Accepted 15 Jan 2019 \\ Key words: \\ Challenges, \\ Governance, Multi- \\ actor, Multi-level, \\ National Health \\ insurance

\begin{abstract}
National health insurance scheme has been used as a strategy to address health inequalities in Ghana in the past ten years. In ensuring all inclusive governance, the government has instituted a system which aims at bringing together various actors at all levels of government. However, little is known about the challenges involved in such multi-level and multi-actor system. In order to open this 'black box', we explored the views of those involved at the district levels to understand the challenges that are associated with this system of governance. We used face-to-face interviews and document review. The study area was Bosumtwi District and the sample size was 25 stakeholders. Data were recorded and later analysed. The findings of the study revealed some challenges which include: working with different set of stakeholders with incompatible interests and divergent goals; the existence of power differentials; limited opportunities for various stakeholders at lower levels to make independent decisions and finally, the problem of coordinated action. It was concluded that while the system is a laudable idea, it would be better if such system helps to bring various actors to existing hierarchical and state-centric apparatuses so as to enhance better coordination of ideas.
\end{abstract}

\section{INTRODUCTION}

In recent times, the traditional government structures, often characterised by strong national states and mostly a vertical structure of decision-making has been transformed by globalization. The transformation is informed by the governance system designed for the past period that has been found to be merely not sufficient for the multifaceted challenges of our contemporary economy and society. Accordingly, for the past twenty years, various governments around the globe have come to believe that the knowledge and skills advancement must be in a state of constant collaboration if governments want to deal with the challenges of the twenty-first century that confront them (Cortada et al. 2008). In the light of this, National policies should no longer be considered without the inclusion of others. In this way, while a number of independent policy programmes are formulated at the central level, the 
4. task for the design and implementation of policy initiatives is more and more entrusted to other levels, both downwards (regional and community) and outwards (market, civil society)( Smith, 2007). Not surprisingly, the policy arena has become more complicated and disjointed as an entire array of establishments and associations have become part of the process of governance. This implies that the national government cannot carry out its national responsibilities all by itself without bringing on board other stakeholders (MacCallion 2007). From the point of view of Khan (2012), the socio-political direction has altered from a hierarchical one, with rules and governmental policy instruments, to a more horizontally defined, exemplified by collaboration and dialogue between actors. Thus, in making policy outcomes more efficient and sustainable, institutions within the political arena have become more reliant on other societal actors and international organisations. The implication here is that the way decisions are made supported by policy tools often depend on partnership and open discussions with actors not only in public but also in the private sectors.

Implicitly, it can be argued that the public policy makers have come to accept that addressing difficult social problems and accomplishing results that are relevant to the community would require the coming together of various actors from not only the public sector but also the private as well. As a result, multi-level and multi-actor governance which is a fresh type of governance has surfaced in all sectors to take over the existing adversarial and administrative kinds of policy making and execution (Tasan-Kok, \&Vranken, 2011).Thus, as governments have come to acknowledge their constraints in solving complex and difficult social problems on their own, the belief that the 'future belongs to those who collaborate' (Economist Intelligence Unit 2007:4), has led to the growth of a multi-level and actor approaches in the wider public and human services arenas which is expected to enhance the working together of a variety of actors (Ansell \& Gash 2008). This means that governance can no more be considered as government but now it entails flexible action and authority dispersed broadly in society (Innes and Booher, 2003). Putting this system into practice, various governments have decided to involve other actors within non-government sector such 
as private firms, the media, philanthropies, community organisations and a variety of non-governmental organisations (NGOs) in the delivery of services as well as the formulation and planning of policies. In essence, currently, governments have been enthralled in higher degrees of both vertical and horizontal collaborations by redefining 'themselves as 'facilitators' engaged in 'value chains' and working through markets, rather than autarkic 'doers' who owned, operated and produced things themselves" (O'Flynn and Wanna 2008: 6 ). In simple terms, what can be said is that rather than making efforts to attain goals that emanate from a top-down influence, members accomplish intended results in a more bottom-up way, due to reflections and their own choice of plan. This means that it is no longer the experts alone that play a direct role in assisting to steer decentralized decision-making, rather it is the contributions and support of citizens that help to find the achievement of policy goals.

Considering this new development in governance in Ghana, it can be noted that over the last decade, there has been a development of fresh networks of actors and strategies at the different levels in the arena of policy decision making process in various sectors, especially in the area of health care service. Historically, Ghana's health care policy has been in the hands of the central government with the main policy decisions taken within policy networks operating at the central government level. This political landscape seemed to have changed. In this sector, as a reaction to the failures of downstream execution and to the high cost and politicisation of public policy directives, government of Ghana has implemented collaborative governance which involved various actors at various levels with the aim of improving the quality of care (Owusu et al., 2013).

With this system, although the central government still preserves substantial powers over policy, there has been some transference to the various levels (regional, district and community). At each level, business and non-governmental actors have become part of political players who contribute in developing sustainable health policy strategies in terms of formulation, implementation and monitoring, and evaluation (Owusu, 2014). Usually, the actors involved work across levels which typify the kind of multi-level governance system existing in the policy arena in the country. The National 
Health Insurance Scheme (NHIS) is an example of a service area where an attempt has been made to improve its service provision by extending the number of the actors involved in policy development and delivery at various levels $(\mathrm{MOH}$ Annual report, 2010). Explicitly, the architect of the NHIS has made a conscious effort of inclusion and collaborative action across a number of spheres of influence and layers of service operation and decision making. However, while this offers an important case study for multi-level and multi-actor governance, the understanding of the challenges involved is lacking. So far, the literature portrays no empirical evidence that could help us to better understand the challenges involved in such complex governance. It is on this basis that this study is conducted.

The paper aims at exploring the challenges involved in multi-level and multiactor governance of NHIS in Ghana from the perspectives of the various actors. Apparently, being the first of its kind, this article will help in filling the knowledge gap in the literature on multi-level and multi-actor governance arrangements and the challenges involved in Ghana in the context of NHIS. Thus, through this study, it is expected that not only will our knowledge in such governance be enhanced but it will also help us to understand more about the true nature of the challenges that are inherent in the novel governance system.

In achieving this goal, the rest of the paper will be as follows: drawing on the existing literature, the second section explains the concept of multi-level and multiactor governance followed by the operation of National Heal Insurance Scheme in Ghana. The third section discusses the research method used to conduct the study. The fourth section concentrates on the study findings discussions and conclusion occupying the final two sections.

\section{LITERATURE REVIEW}

\section{1, The concept of multi-level governance}

From the perspectives of Tasan-Kok and Jan Vranken (2011) multi-level governance (MLG) can be defined as: 


$$
\text { "arrangement for making binding decisions that engages a }
$$

multiplicity of politically independent but otherwise interdependent actors private and public - at different levels of territorial aggregation in more-or-less continuous negotiation/deliberation/implementation, that does not assign exclusively policy competence or assert a stable hierarchy of political authority to any levels".(p.6)

This implies that MLG concentrates on the diffusion of governance across several authorities, such that numerous stakeholders at dissimilar levels are involved in decision-making (Hooghe \& Marks, 2002). Bache and Flinders (2005) opine that the main characteristic of MLG is that there is a "dispersion of central government authority both vertically to actors located at other territorial levels, and horizontally, to non state-actors" (p. 4). However, as argued by Bevir (2009) both the horizontal and vertical connections are not inhibited by conventional jurisdictional boundaries. From the perspectives of t'Veld and Roland, (2011), although traditional government model gives respect to borders between public and private actors with hierarchy and regulatory powers also kept for public actors, governance is not solely ascribed to the government.

In effect, it can be stated that at the core of the MLG agenda is the fact that in a growing number of policy arenas, there is no particular actor that has complete competence. This assertion is supported by Marks et al, (1998) who argue that 'the point of departure for the multi-level governance approach is the existence of overlapping competencies among multiple levels of government' (p: 41). This argument is actually true when it comes to decision making process where competencies can be considered as a shared property amongst a multiplicity of actors located at various territorial levels, rather than dominated by central governments (Hooghe $\&$ Marks, 2001).This does not mean to say that the central government is no more the commanding actor. Instead, it is not the only actor that has the sole control over the national policy making process. Therefore, whereas the state executives can be seen to be powerful, they are not the only one amongst a number of actors, for example, in the Ghanaian polity. In the context of a bottom-up perspective as it is in 
NHIS in Ghana, this state of affairs demands synchronization of the activities of various actors. In a way, MLG can be seen as a mechanism to improve the understanding of decision-making.

Based on the ideas of t'Veld and Roland (2011), MLG can be seen as an approach essentially meant to be used for system of government that has the probability of being hierarchical, market and network governance. This is because it helps to bring a combination of "reasoning, knowledge, responsibility, awareness, engagement and action" (Szydarowski \& Tallberg, 2013, p.4). However, Peter and Pierre (2004) caution that the multi-level governance might make democratic values fragile and with less possibility of sustaining it in terms of the decision-making.

\section{2, Multi-actor governance (MAG)}

According to Bache and Flinders, (2004), multi-actor governance (MAG) is the situation where a number of public and community actors belonging to diverse decision levels and at the same time are joined together through cooperative relationships and collaborative actions come together to plan, design and execute public policies. The idea here is that a multi-actor governance (MAG) approach accepts non-governmental actors to take diverse steering initiatives through formal and informal exchanges and networks in collaborative systems (Vermeesch et al. 2013. p.2).

In the context of this study, these non-state actors include non-commercially orientated NGOs, profit-making organisations like both the Christian and individual hospitals who are health care providers, pharmacies and communities. These non-state actors stand for a range of interests and discourses with their activities happening at various levels, varying from local to national. These actors, according to Keck and Sikkink (1999) are "political entrepreneurs" who are significant players that execute diverse roles, including information sharing; capacity building and implementation; and rule setting (Andonova et al., 2009). In essence, non-state actors play different roles across the entire policy spectrum, starting from formulation through influencing 
policy makers to taking action that is free from the interference of the states (Nasiritousi, Hjerpe \& Linner 2014).

\section{3, The National Health Insurance Scheme in Ghana (NHIS)}

Historically, the current NHIS, which has become a modern health care financing in Ghana, has gone through different changes over the decade. For example, while in the pre-independence era, there were largely out-of-pocket payments (Arhinful 2003), post independence period ushered Ghanaians into "free health care for all" policy (Ghana Health Service, 2009). For Private sector health services, out-of-pocket fees at a point of service usage were charged (Agyepong \& Adjei, 2008). With this system while the financial aims of cash and carry system were achieved there werestern inequities in financial access to basic and essential clinical services (Waddington $\&$ Enyimayew 1990: 287-312). Challenges within the health sector prompted some health care facilities, mainly mission hospitals, to introduce insurance schemes managed jointly with communities (Creeseand Benneth1997). E.g. the Nkoranza scheme which was the first Mutual Health Insurance Scheme (MHIS) in Ghana, was initiated by the Catholic Diocese of Sunyani in 1989. Other schemes, such as Damongo and Dangme West MHIS became models for other communities to imitate(Creeseand Benneth 1997).

Having identified the problems faced by Ghanaians, especially those in the poor rural communities to access health care, the Government of Ghana, commissioned various studies into alternative health financing, principally insurancebased in an effort to ensure equitable accessibility to health care in the country. Consequently, the NHIS bill was passed into law in 2003, which gave birth to NHIS with the aim of offering health care financing alternatives that guarantee that the bigger society benefit from the scheme which takes away the existing up-front payments and instills confidence in the health system. Thus the insurance was considered as a private or public system of protection against the losses owing to medical expenses (NHIA, 2008). It is based on the principle of pooling of risk, and therefore, the redistribution of financial resources from the segment of a community 
that does not incur high health care cost to those segments of the community that cannot afford the costs involved in attending hospitals (NHIA, 2008).

In terms of governance the scheme is hierarchically organized and horizontally diverse. It is governed by a 16-member Council drawn from various stakeholder organisations $(\mathrm{MOH}, 2014$ Annual Report). Functionally, similar to its mother organisation, the Ghana Health Service, the NHIS is organised at five levels: national, regional, district, sub-district and community. The national level is the head of the scheme which formulates and oversees the implementation of the scheme's policy strategies. The regional level is only a coordinating body acting as a bridge between the national and the district levels. The District level is the implementer of policy strategies and it has been sub-divided into towns and communities. At the lower level, the coordinating body is the health insurance committee with five committee members. Thus, to ensure accountability to stakeholders, NHIS is decentralised to the regional and district levels (NHIS, 2003 ACT 650).

From the NHIS ACT 650, it can be noted that although the structure has multi-level character with a centralised administrative system, the decentralisation of the government and health sector reform which allow the participation of the lowest level, services are now integrated from the national level to regions, districts, subdistricts and communities. This has also led to the involvement of multi-actors which include the private individuals who are providers, the NGOs and other providers from the various faith-based organisations essentially from the Christian Health Association of Ghana (CHAG) who is part of a non-governmental organisation that brings together churches that offer health services $(\mathrm{MOH}, 2014)$.

From the literature, it can be argued that there is a multi-level and multi-actor governance arrangement which has the potential to create a number of challenges. In this paper, these challenges are explored from the perspectives of the actors involved in the governance for NHIS in Ghana. 


\section{RESEARCH METHODS}

With the intention to have an in-depth understanding of the problem, a qualitative method was employed. To this end, face-to-face semi-structured interviews were used to collect data. The data were collected from August 2015 to October 2015 in the selected area in Ghana.

\section{1, The study area}

The study was conducted in the Ashanti Region of Ghana at the Bosumtwi District which is one of the 138 districts in Ghana at the moment. The rationale for selecting this district was based on realistic considerations. One of such consideration was the easy accessibility to the background information. Secondly, the reseachers' knowledge and ability to speak the local language, as well as the friendly research network that was available to fall on during the study was a contributing factor. Thus, the chances of having the potential respondents' assistance from the NHIS policy actors and the communities in that district were relatively higher than most of the districts within the region.

\section{2, The size of the study population}

The number of people interviewed was 25 . The first 14 interviewees were chosen from the DHIS centre at the district head office which included 8 senior and6 junior policy administrative actors. With regards to the providers, 5 health workers were interviewed at the faith-based hospital, St. Michael's Hospital at Jachie-Pramso and 2 Private healthcare providers were also selected. Finally 4 committee members of NHIS from the community were also interviewed.

\section{3, Data Collection Method}

The research data was collected through the use of semi-structured interviews. Various groups of interviewees who were considered as stakeholders and had good knowledge about the NHIS at the District level were purposively selected and were interviewed. 
Interviews lasted between 30 and 45 minutes. For the sake of confidentiality, the names of the interviewees were obscured and as such numbers 1-25 representing the interviewees were employed.

During the interview, interviewees' responses were audio-taped and at the same time notes were instantly taken after spending time with the interviewees. In the course of the exercise of writing up of field notes, attention was paid to "who" the actors were and the meanings of the statements made in the context of the setting.

In the analyses, besides the use of the field notes, the entire data that was audio-taped was transcribed and examined for the various themes that emerged. These emerged themes were put into a number of categories and are discussed below.

\section{4, Data Analytical Tool}

In analyzing our interview data we employed constant comparison analysis (CCA) propounded by Glaser and Strauss (1967). CCA was deemed appropriate for this research because we were interested in utilizing the entire dataset to identify underlying themes revealed through the data, which is a tenet of CCA (Leech and Onwueguzie, 2007). As an important tenet of CCA, the authors read through the entire data after which we grouped the data into smaller meaningful parts by labelling data into disruptive titles. Texts or narrations as provided by interviewees were therefore sorted, and grouped under each title or theme to reveal how the sets of texts supported or revealed the relevance of the themes to help achieve the research objective.

Although CCA was oringinally developed to analyse data that were collected over multiple rounds (Charmaz, 2000), the analytical tool has since been modified to suit analysis of data collected in one round (Leech and Onwuegbuzie, 2007) as in the case of our research. In all, we developed four themes or titles, under which we presented (similar) texts to support or strengthen the themes, leading to their descriptive validity or accuracy. 


\section{PRESENTATION OF FINDINGS}

The study outcomes portrayed various challenges that were considered to be involved in the multi-level and multi-actor governance of national health insurance scheme in the district. These challenges are discussed in details below.

\section{1, Working with different set of stakeholders with incompatible interests}

\section{and divergent goals}

From the interview it was discovered that one major challenge facing the scheme is the problem of working with different sets of stakeholders with irreconcilable differences in the interests and goals. The fact of the matter is that the goals of the stakeholders who are from the private sector are not the same as those from the third sector (i.e, the NGOs) as well as the public sector which is the state. It was revealed that while the private sector aims at sustaining their profits and getting value for their products, the goal of the NGOs and the state has been to deliver services devoid of profits to the general public. This was evident in the narration below as provided by a policy actor

"How can people from different backgrounds work together when one often needs to compromise ones interest to serve the other. Private sectors are interested in making profit while the public sector or the state is interested in providing services without considering the cost. These two are not possible". (Participant 2)

This incompatibility of stakeholders was assigned by other participants that the fact that both public and private sector were not looking at issues in the same way meant that both would always have difficulties in arriving at the same conclusion. The two quotation below justify this "We those in the private sector will always seek for our economic interest irrespective of the impact on the community members while others with the support they get from either donors or governments will reason along the humanitarian grounds and would not care about the losses they would make. (Participant 5)

According to one stakeholder, "the different backgrounds, coupled with different areas of interests are the ones that make working together very demanding for each one of us."(Participant 1) 
The above arguments clearly depict that with the disparities in interests and goals between private and public sector stakeholders, achieving consensus in such multi-actor scheme will be difficult as in the case of NHIS. The underlying reason for this outcome as argued by Moulaert et al. (2001) is that to make compromises and to compare interests consume much longer time and energy and therefore economically costly to individual policy actors. This situation re-enacts a difficulty when it comes to the need to stress on social advancement as a result of poor provision of services as such demand produces conflict between the public and private sector actors because it is an agenda that is not often found in the private sector. This argument is supported by one actor who stated that:

"goals differences render the entire governance process really problematic because it is not easy to keep the various actors focused on the key issue that needs to be addressed.(Participant 20)

The idea expressed in the above quotation suggests that ensuring commitment from all important stakeholders and sector diversity will not be easy since some of the organizations involved in the multi-actor governance have the motive of satisfying their shareholders by making profits while others only consider the welfare of the citizens. Such disparities are likely to limit the capacity and willingness to invest resources, particularly time and dedicated staff in the governance process. This has important implications for the attainment of an effective coordination and collaboration among the actors. This suggests there should be synergy building to balance the opposing demands of the actors which collaborates the view of Saavedra, and Knox-Clarke (2015) that there are trade-off that needs to be made for vigorously engaging coordination and responding to immediate needs which have an effect on priorities.

\section{2, The existence of power differentials}

Another challenge that was perceived to be prevailing was power differential that exists among the stake holders. According to the views shared by most of the interviewees although ground-level relations amongst staff and community appeared to be objectively acceptable, characterised by trust, there is still the problem associated with the hierarchical nature of the governance. Most interviewees argued that there 
has been existence of power-relations gap among those at the community level and those at the district, regional and national levels. According to one actor,

"while relationship among stakeholders is good, making a decision based on the recommendations from the superiors often cause problems. It creates distrust and a situation where most of us do not feel part of the decision making process" (Participant 19)

Another actor expressed similar concern by arguing that

"the differences in power possession within the system seems to suggest that those of us who are at the bottom level are to conform to the decisions of our superiors at the higher levels. This does not augur well for mutual respect"(p17)

From the above assertion, it can be said that multi-actor working has not been a problem per se at the lower level, but the multi-level system is creating problems of cordiality and better collaboration that need to be addressed. Thus, the strong argument against the very idea of working closely together cannot be seen in the context of multi-actor governance system alone, but the existence of major power disparities which exist between different actors at the various levels of governance. This argument was supported by the argument made by one actor who asserted that...

"We have a system which makes it possible for those who are weak to work and interact with those who are more powerful than they are when it comes to decision making. In that circumstance there is a potential danger that those less powerful ones will be obliged to give concession on their goals, values and beliefs....And this is what is happening, community members and maybe NGOs usually have to give in to the wishes of those at the top of the decision-making ladder. This is not sustainable"(Participant 15).

The idea inherent in the above quotation depicts that most of the interviewees are concerned about the power structure that exists in the multi-actor and multi-level governance. Although the efforts of the local-level communication could be appreciated, the responses of the interviewees demonstrated that there has been a lack of in-depth communication from all sides, especially regarding tactical deliberations.

\section{3, Limited opportunities for various stakeholders at lower levels to make independent decisions \\ Another challenge identified in the multi-level and multi-actor health governance was lack of opportunities for various stakeholders to make independent}


decisions causing potential risk of various stakeholders losing their unique dispositions. This challenge was revealed in the following:

"We all think the same because we accept everything that is said by those at the higher positions. We hardly challenge anything that is said by our superiors because we have no means to do so. Decision is mostly from one source and we are not given enough space to make contributions. In this way, we lose our identity and creativity. Such system often defeats the very purpose of standing in for the community" (Participant 13)

The idea here is that individual actors at the lower levels often lose their independence in their thinking since they are detached from their own beliefs and values. This happens because there is a limited opportunity for them to bring out their own ideas. Thus, whereas uniformity has the potential to intensify policy effectiveness, it can also reduce proper discussion, choices and advancement, and eventually sow the seed of a form of system-wide 'group think' which can be ineffective (Saavedra, and Knox-Clarke, 2015)

This lack of practical space for diverse actors to operate, is also expressed as follows:

"It creates confusion thereby making the whole idea of having many actors working together not beneficial. In fact, such governance cannot be said to be a perfect system that can enhance clearness, accountability and democracy" (Participant 8)

In this way, it can be said that while multi-level and actor governance can be critical in many situations, it does not allow those at the lower levels to have the chance to work in an impartial and autonomous way. Consequently, any attempt to prioritise issues will also lead to relegation of those at the lower levels' priorities to the background.

\section{4, The problem of coordinated action}

The final challenge perceived to be inherent in multi-level and multi-actor governance is the problem of coordination. On this issue it was realised that the participation of a number of actors promotes difficulties which requires co-ordination 
and yet hardly do stakeholder coordinate their activities. This problem is echoed with the narration below:

"We hardly coordinate activities understandably because of the nature of the system. In a situation where there is this intricate structure, coordinating activities among we the different stakeholders has been challenging" (Participant 4)

The problem of lack of coordination re-enacts a problem of uncertainty due to lack of control over what discussion to make and when to make it. This is revealed with the narration below:

"The nature of the system demands a coordinated action for all of us to appreciate the direction of the scheme and to have a smooth working, but a coordinated action has been a major problem. Many of us hardly know when the next instruction will come and what type of guidelines will come with such instruction" (Participant 6)

Implicitly, what the above quotations suggest is that the governance system which involves several actors at various levels often brings about disjointed decisionmaking and uncertainty over such decision should be taken which do not augur well for a harmonised action. Also the disintegration of responsibilities among stakeholders due to the nature of the system leads to lack of coordinated action. The fact is that because most of these stakeholders are from various organisations, there is no motivation to share a common vision and as such the parties involved do not ensure stability and interconnectivity in their plans that will enhance better progress of the scheme

\section{IMPLICATIONS OF FINDINGS}

The qualitative data coded and presented with the previous section has revealed mainly

perceived challenges involved in multi-level and multi-actor governance. These challenges from our findings include the problem of working with different set of stakeholders with incompatible interests and divergent goals; the existence of power differentials; lack of opportunity for various stakeholders to make independent decisions and finally, the problem of coordinated action 
These challenges demonstrate that while multi-level and multi-actor can be a good system which can enhance collaborative management, according to Harman, (2010), its highly centralised nature of decision-making makes it a state-centric, hierarchical form of organization which is built on a division of disproportionate power sharing. The study result has revealed that the creation of power in multi-level and multi-actor governance perpetuate the restriction of those at the lower levels' power in terms of agenda-setting and decision-making particularly the communities. This restriction also leads to lack of coordination amongst the actors. This phenomenon is one of the actual challenges of multi-level governance. There seems to be no ground-level communication causing lack of participation of the major players at the lower levels in the decision making process.

However, putting the central government at the core of multi-level and multiactor health governance, according to Harman (2010) paves way for a re-enforcement of the 'blame the state' (p.4) way of thinking. This means that there is always a general wrong perception about the central government that has to be blamed for any unsuccessful programme because the central state is charged with the task of coordinating affairs with the other important players such as the private, nongovernmental and the communities. In any case, this kind of challenges cannot be seen to be a problem considering the nature of the culture that we have in Ghana. Based on Hofstede and Hofstede (2005), culture in Ghana can be characterized by high power distance with the most frequently employed management approach being an autocratic one i.e. high power distance. In this situation, both the managers and the subordinates regard each other as existentially not the same, which results in broad approval of the discernible sign of the status (pp. 55-56). Thus, the cultural context plays a significant function in a decision making process in Ghana which makes the superior the person who more usually formulate decisions without those at the lower level taking part while the exact orders are given to those at the lower rank as to how decisions are to be executed (Hofstede 2000). In the case of NHIS scheme, the task for decision making is seen to be in the hands of those employees at the higher levels, specifically those at the national levels. This should be tolerated by those at the lower 
level because in Ghana such power imbalance can not only be accepted but also considered as something normal. Moreover, in Ghana subordinates are afraid of punishment should they refuse to agree with those at the management position's decision. We therefore speculate that the challenges that confront the multi-level and multi-actor governance system of NHIS are not easy to be addressed, particularly considering the culture of Ghana. In this sense for those identified challenges to be dealt with, there is the need for cultural change which can ultimately change the way we accept those problems.

\section{CONCLUSION}

This study has produced important insight into the challenges involved in the multi-level and multi-actor governance system of NHIS, which makes our research objectives achievable to larger extent. The study results indicate that while the system could be seen to be a mechanism to bring on board many stakeholders which can be seen to be a laudable idea, there are several challenges that have been perceived to be associated with the system. In effect, the system of multi-level and multi-actor health governance offers a difficulty for the governance of NHIS as against its expected solution of the problem of health care provision in Ghana. This assertion is based on: the working together of different set of stakeholders with incompatible interests and divergent goals; the existence of power distance; lack of opportunity for various stakeholders to make independent decisions and finally, the problem of coordinated action. These challenges have come about as a result of the system's centralised and hierarchical nature. Though there is room for creativity in sharing ideas it is within a narrow structure defined by those at the higher level. Therefore the system fails to provide an opportunity for broader participation of those at the lower levels which appears to be embedding practices of bad governance characterized by uncertain decision-making process, unclear separation of power, and stakeholders' perfect participation and accountability deficiency. Consequently this type of governance has significant impact on most of the programmes and structures in which NHIS governance become executed. 
In a nutshell, it can be said that while the multi-level and multi-actor governance of NHIS offer another good way of governing it does have its own challenges. it is our belief that, ideally, it would be better if such system helps to bring local communities and the private sector to existing hierarchical, state-centric apparatuses of encouraging laissez-faire democracy which can enhance better coordination of ideas. This suggested type of governance will go a long way to minimise the mentality of always accusing the state for the failure of health management system since the community groups and private individuals will also be accountable to any failure that will occur.

\section{REFERENCES}

Agyepong, I.A and Adjei, S (2008)Public social policy development and implementation: a case study of the Ghana National Health Insurance scheme, Health Policy and Planning; 23:150-160

Andonova, L., Betsill, M., \&Bulkeley, H. (2009).Transnational climate governance. Global Environmental Politics, 9(2), 52-73.

Arhinful, D.K. (2003). The Solidarity of Self-Interest: Social and Cultural Feasibility of Rural Health Insurance in Ghana. University of Amsterdam, Doctoral Thesis

Ansell, C. and A. Gash. 2008. Collaborative governance in theory and practice. Journal of Public Administration Research and Theory, 18(4): 543-71.

Bache, I. and Flinders, M. (eds) (2004) Multi-level Governance, Oxford: Oxford UniversityPress.

Bevir, M. (2009), Key concepts in governance. Thousand Oaks, CA: SAGE Publications

Cortada, J. W., Dijkstra, S., Mooney, G. M. and Ramsey, T. 2008, Government2020 and the Perpetual Collaboration Mandate: Six worldwide driversdemand customized strategies, IBM Institute for Business Value, IBM Global Services, New York.

Creese, A.; Bennett, S. (1997), Rural Risk-Sharing Strategies. In: Schieber, G.(ed.),Innovations in Health Care Financing. Proceedings of a World Bank Conference,M arch 10-11, 1997, Washington, D.C

Economist Intelligence Unit (2007) Collaboration: Transforming the way business works. A report from the Economist Intelligence Unit White paper sponsored by Cisco Systems, April edition, 1-34

Ghana Health Service (2009).Annual Report.M inistry of health, Accra.Ghana

Harman, S (2010) Looking for alternatives in global governance: why multi-level health

governance is not the answer for poverty reduction. Working Paper CUTP/007

Hofstede, G. (2000). Culture's Consequences.Second Edition. Comparing Values, Behaviors, Institutions, and Organizations across Nations.International Educational and Professional Publisher. Thousand Oaks.

Hofstede, G. \& Hofstede, G. J. (2005). Cultures and Organizations: Software of the Mind

(Rev. 2nd ed.). New York: McGraw-Hill. 
Hooghe, L. 1996. Cohesion Policy and European Integration: Building Multilevel

Governance. Oxford: Oxford University Press.

Hooghe, L., \& M arks, G. (2002).Types of multi-level governance. Cashiers Européens de Sciences P.3.

Innes, J., \& Booher, D. E. (2003). Collaborative policy making: Governance through dialogue. In M. Hajer\& H. Wagenaar (Eds.), Deliberative Policy Analysis: Governance in the Networked Society (pp. 33-59). Cambridge: Cambridge University Press.

Keck, M. E., \&Sikkink, K. (1999). Transnational advocacy networks in international and regional politics. International Social Science Journal, 51(159), 89-101.

Khan, M. H. (2012). 'Beyond Good Governance: An Agenda for DevelopmentalGovernance'. In J. K. Sundaram and A. Chowdhury (eds), Is Good Governance Goodfor Development?, London: Bloomsbury Academic.

MacCallion, S ( 2007). Multi-Level Governance in Sweden ? Regional \& Federal Studies, $17(3), X X X X X$

Ministry of Health (2010) Strategic Overview of the Ministry of Health, Annual Report, Accra, Ghana

Ministry of Health, (2014) - Holistic Assessment of 2013 Programme of Work Annual Report

Marks, G., Hooghe, L. and Blank, K. (1996) 'European Integration from the1980s: State-Centric v. Multi-level Governance' Journal of Common MarketStudies, 34(3): 341-378.

Marks, G., Neilsen, F., Ray, L., and Salk, J. (1998) 'Competencies, Cracks andConflicts: Regional Mobilization in the European Union.' In G. Marks, F.Scharpf, P. Schmitter, and W.

Streek (eds.) Governance in the European Union. London: Sage Publications Ltd: 40-63.

Moulaert F, SalinE,Werquin T, 2001, ' Euralille. Large-scale urban development and social polarization" European Urban and Regional Studies $8145 \& 160$

Nasiritousi, Hjerpe and Linner (2014) The roles of non-state actors in climate change governance: understanding agency through governance profiles, International Environmental Agreements: Politics, Law and EconomicsVolume 16, Issue 1, pp 109_ 126

National Health Insurance Act, 2003 (ACT 650).NHIS ACT 650)

O'Flynn, J. and J. Wanna (eds.), 2008. Collaborative Governance: a new era of public policy in Australia? Australian and New Zealand School of Government and ANU E-Press, Canberra.

http://press.anu.edu.au/wp-content/uploads/2011/06/whole_book4.pdf (Accessed 20 May 2016).

Owusu, N.O., Baffour-Awuah, E; FifiAmoako, J, Mohan, J. and Madise, N.J. 2013). "Examining intersectoral integration for malaria control programmes in an urban and a rural district in Ghana: a multinomial multilevel analysis", Int J. Integrated Care, 13(July-Sept): 1-10.

Owusu and Owusu (2014) Ghana's System of Local Government Administration As a Barrier to Collaborative Public M anagement, Journal of Contemporary Management Vol. 4, No. 1

Peters, G. and Pierre, J. 2004. 'Multi-level Governance and Democracy: A Faustian Bargain?'In I. Bache \& M. Flinders, (eds.) Multi-level Governance, Oxford: Oxford University Press: 7489

[31] Saavedra, L. and Knox-Clarke P. (2015). Working together in the field for effective humanitarian response. ALNAP Working Paper. London: ALNAP/ODI. 
Smith, B. (2007). Good Governance and Development. New York, NY: Palgrave M acmillan.

Tasan-Kok, T \&Vranken, J (2011) : Handbook for M ulti-level Urban Governance in Europe Analysing Participatory Instruments for an Integrated Urban Development multi-level governance a European experience and key success factors for transport corridors and trans border integration areas

Task report, 9 April

t'Veld and Roland J. (2011) Transgovernance: the quest for governance of sustainable development. First report of the TransGov project of IASS, Potsdam

Vermeesch, I; Craps, M; Dewulf, A; Termeer, K (2013): Relational perspective on leadership in multi-actor governance networks for sustainable materials management. Towards a framework based on Complexity Leadership; $A$ Paper presented at the 1st International Conference on Public Policy

Grenoble, June 26-28,

Waddington C.J and Enyimayew K.A (1990) "A Price to pay, part 2: The impact of user charges in the in the Volta Region Ghana, International Journal of Health Planning 